\title{
No Time Like The Present: Determinants Of Intentions To Engage In Bystander Anti-Racism On Behalf Of Indigenous Australians
}

\author{
Yara Frias Neto and Anne Pedersen \\ Murdoch University, Perth, Western Australia, Australia
}

\begin{abstract}
The present study explored whether variables previously shown to relate to pro-social attitudes and behaviours could be applied to the intention to engage in bystander anti-racism on behalf of Indigenous Australians. 149 non-Indigenous participants were asked to indicate how likely they were to engage in bystander anti-racism in response to an 'everyday' racial discrimination scenario presented within an online survey. Being female, older, and politically left leaning correlated with bystander anti-racism intentions, as did higher levels of collective guilt, anger, empathic concern and lower levels of prejudice. Regression analysis revealed that being older and having higher levels of empathic concern predicted the intention to engage in bystander anti-racism. While it may seem rational that the ability to feel for the plight of another (empathic concern) is necessary for bystander anti-racism to ensue, older individuals may feel more competent in their ability to effectively intervene.
\end{abstract}

Keywords: everyday racism, Indigenous, bystander, anti-racism, pro-social

Disadvantage on the basis of race is pervasive (e.g., Larson, Gilles, Howard, \& Coffin, 2007; Paradies, Harris, \& Anderson, 2008). In Australia, Indigenous Australians have been marginalised since the arrival of the first fleet in 1788 (Bourke \& Cox, 1994) and continue to face social and institutionalised racial discrimination (Henry, Houston, \& Mooney, 2004; Mooney, 2003). Racism can be defined as 'that which maintains or exacerbates inequality of opportunity among ethnoracial groups, and can be expressed through stereotypes (racist beliefs), prejudice (racist emotions/affect) or discrimination (racist behaviours and practices)' (Berman \& Paradies, 2010, p. 4).

For Indigenous Australians, the effects of racial discrimination can be seen in a variety of outcomes, including poor levels of educational attainment (Australian Bureau of Statistics [ABS], 2008), reduced earning capacity (ABS, 2006a), difficulties with housing (Beresford, 2001), inferior quality of health care (Henry et al., 2004), overrepresentation within the prison system (ABS, 2009), and significantly lower life expectancy than non-Indigenous Australians (ABS, 2006b). Discrimination also significantly impairs the physical and psychological wellbeing of Indigenous Australians (Larson et al., 2007; Paradies et al., 2008), with some responding to racial discrimination by withdrawing from society, engaging in drug and alcohol use, and by internalising racism (Mellor, 2004). Clearly, there is a great need to establish equality between Indigenous and non-Indigenous Australians with a focus on putting an end to racism and discrimination.

\section{Bystander Anti-Racism}

The possibility of using bystanders to intervene in acts of discrimination has recently led to the investigation of bystander anti-prejudice (e.g., Swim \& Hyers, 1999; Good, Moss-Racusin, \& Sanchez, 2012), and more specifically bystander anti-racism (e.g., Pedersen, Paradies, Hartley, \& Dunn, 2011a; Pedersen, Walker, Paradies, \& Guerin, 2011b). Bystander anti-racism can be defined as action undertaken by a witnessing individual (not the target or perpetrator) to challenge and ultimately stop instances of interpersonal or institutionalised racism (Nelson, Dunn, \& Paradies, 2011).

As bystander anti-racism involves the average person challenging instances of discrimination, it is especially well placed to target 'everyday' racism (Beagan, 2003; Swim, 
Hyers, Cohen, Fitzgerald, \& Bylsma, 2003), which occurs at a social or interpersonal level outside the reach of policy (Nelson et al., 2011). Everyday racism can be understood as disparaging innuendos, acts, beliefs, or attitudes about a given racial group that are encountered on such a regular basis that their offensive and damaging nature is often denied, downplayed, or not recognised by those who are not targets (Bloch \& Dreher, 2009; Dunn \& Nelson, 2011; Swim et al., 2003).

\section{Outcomes of Bystander Anti-Racism}

Aside from the immediate aim to obstruct and stop racial discrimination, one of the suggested key and longer term outcomes of bystander anti-racism is its ability to establish anti-racism norms (Nelson et al., 2011). Researchers have long reported that people tend to behave in accordance with standards set by others (e.g., Asch, 1955, 1956; Crandall, Eshleman, \& O’Brien, 2002). These standards are referred to as norms and are communicated through social interaction (Cialdini \& Trost, 1998).

Norms inform us about what behaviours are and are not considered acceptable. Research suggests that hearing just one person express a given opinion or attitude is sufficient to influence the opinions and behaviour of others (Blanchard, Lilly, \& Vaughn, 1991). This has implications for the possible effect of bystander action as well as that of bystander inaction. When bystanders speak up, it may be possible to establish anti-racism norms. Yet, on the other hand, bystander inaction means that the prejudiced opinions of the perpetrator are given 'air time' and may influence other witnesses and establish or maintain pro-racism norms (Masser \& Phillips, 2003).

Other lines of study indicate that being confronted about racist behaviour triggers feelings of guilt, concern for the welfare of the target, and apologetic responses from perpetrators (Czopp \& Monteith, 2003). In addition, some researchers have found that being confronted about racist behaviour reduces the likelihood of such behaviour being repeated in the future, as well as a reduction in the prejudice levels of the perpetrator (Czopp, Monteith, \& Mark, 2006). Thus, it seems probable that bystander antiracism may not only provide the basis for anti-racism norms, but may also reduce the likelihood of future racist behaviours.

Finally, the fact that highly prejudiced individuals tend to overestimate social support for their views (e.g., Pedersen, Griffiths, \& Watt, 2008; Watt \& Larkin, 2010), and are more willing to publicly behave in ways that reflect their prejudices (Miller, 1993), implies that bystander antiracism may be an effective tool for challenging the false consensus beliefs of highly prejudiced individuals. In summary, bystander anti-racism shows promise as a means of effectively challenging racial discrimination. Yet there is limited research that has explored its possible correlates and predictors.

\section{Potential Predictors of Bystander Anti-Racism}

As bystander anti-racism can be thought of as a specific form of pro-social behaviour, research on pro-social behaviour is well positioned to suggest potential predictor variables. Furthermore, as attitudes tend to direct behaviour (Ajzen \& Fishbein, 2005; Glasman \& Albarracin, 2006), research on pro-social attitudes may also be relevant. Variables identified as possibly relevant to bystander anti-racism are discussed below.

\section{National Identity}

Social identity theory (SIT, Tajfel \& Turner, 1986) posits that in social situations we often operate according to our social identity. Tajfel (1974) defines this social identity as 'that part of an individual's self-concept which derives from his [sic] knowledge of his membership of a social group (or groups) together with the emotional significance attached to that membership' (p. 69). One's group will from hereon be referred to as the 'ingroup', while the 'outgroup' refers to a group whose membership one does not share.

As individuals strive to feel good about themselves and their group membership (Tajfel \& Turner, 1986), they are motivated to act positively towards their ingroup. In support of this assumption, many researchers have indeed found that individuals are most likely to help those who belong to their ingroup (Cuddy, Rock, \& Norton, 2007; Levine, Prosser, Evans, \& Reicher, 2005; Tarrant, Dazeley, \& Cottom, 2009) and to engage in pro-social action on behalf of their ingroup (Klandermans, 2002; Levine \& Thompson, 2004)

Of course, individuals belong to a variety of social groups. For example, one may identify as a woman, a student, an Australian, and with a great deal of other social groups. SIT proposes, however, that one's behaviour in a given context is influenced by the group identity that is salient in that moment (Terry \& Hogg, 1996). Building on this with respect to bystander anti-racism, it is possible that when racism is expressed, one's racial identity is most salient as such expressions may trigger comparisons between the bystander and the target which make prominent their differences or similarities with respect to race.

Research suggests that Indigenous Australians are not incorporated into the mainstream image of Australian national identity (Sibley \& Barlow, 2009; Fraser \& Islam, 2000). This implies that the Australian identity may be racially defined, differentiating between Indigenous and non-Indigenous Australians. Based on these assumptions, it is feasible that the likelihood of a non-Indigenous Australian engaging in bystander anti-racism on behalf of an Indigenous Australian may depend on their level of national identification. This possibility, however, is yet to be explored. 


\section{Collective Guilt}

Collective guilt refers to negative feelings which arise from the perception that the actions of other ingroup members are incongruent with the norms or values of the group (Doosje, Branscombe, Spears, \& Manstead, 1998). Rather than feeling personally responsible, individuals experience guilt on behalf of the group with which they identify (Iyer, Leach, \& Pedersen, 2004; Thomas, McGarty, \& Mavor, 2009). Given the history of discrimination and mistreatment of Indigenous Australians by non-Indigenous Australians (Bourke \& Collins, 1994), collective guilt may be especially relevant to relations and interactions between these groups.

Collective guilt has been shown to predict support for gay and lesbian anti-violence programmes (Karacanta \& Fitness, 2006), the compensation of Indonesians in regards to disadvantage ensuing from Dutch colonisation (Doosje et al., 1998), government apology with respect to Australia's history of discrimination towards Indigenous Australians (McGarty et al., 2005, Studies 1 and 2), reconciliatory attitudes and behaviours within the context of Indigenous Australian history (Halloran, 2007), and reparation attitudes with respect to the Indigenous Chilean history (Brown, Gonzalez, Zagefka, Manzi, \& Cehajic, 2008). More recently, Pedersen and Thomas (2012) reported that collective guilt was one of the two emotions most cited by participants when reading about racial discrimination scenarios.

On the other hand, as collective guilt is a self-focused emotion (Iyer et al., 2003), some authors argue that it may be limited when it comes to pro-social behaviour (e.g., Iyer et al., 2004; Thomas et al., 2009). Collective guilt arises from a concern about the involvement of one's group in the mistreatment of another; therefore, it is focused on the self and not the 'other'. For this reason, it may be that collective guilt can motivate behaviours (such as contribution to financial compensation) that are aimed at reducing the aversive feelings of guilt for an individual, but not those which are aimed at improving the long-term conditions for disadvantaged groups.

\section{Empathic Concern}

Empathic concern is the emotional response to the perceived welfare of another (Thomas et al., 2009; Stephan \& Finlay, 1999) and specifically involves feeling for another and their situation (Iyer, Leach, \& Crosby, 2003). Unlike collective guilt, empathic concern is an other-focused emotion (Iyer et al., 2003). As such, it should be especially effective in motivating behaviours that are aimed at restoring equality between advantaged and disadvantaged groups (Iyer et al., 2004; Thomas et al., 2009).

As bystander anti-racism involves speaking up to stop the discrimination of another, it seems logical that concern for the welfare of the target might motivate bystanders to act. Supporting this logic, empathic concern has been shown to improve attitudes towards minority
(Vescio, Sechrist \& Paolucci, 2003) and stigmatised groups (Batson, Chang, Orr, \& Rowland, 2002; Batson et al., 1997), and to be associated with or predict a variety of pro-social behaviours (Eisenberg \& Miller, 1987) such as volunteerism (Oswald, 1996), support for equal opportunity and compensatory programmes for African Americans (Iyer et al., 2003, Study 2), greater allocation of funds for target support services (Batson et al., 2002), and greater intentions to volunteer in gay and lesbian anti-violence programs (Karacanta \& Fitness, 2006).

That empathic concern follows only when one is focused on the other (Harth, Kessler, \& Leach, 2008; Iyer et al., 2003, Study 2) may be especially pertinent within the bystander anti-racism context. By virtue of being a bystander to instances of racial discrimination, it is possible that one's attention or focus may automatically be drawn to the target (other). It is suggested that this initial focus on the other leads to intergroup comparisons that result in the perception that, relative to the ingroup, the outgroup is disadvantaged (Leach, Snider, \& Iyer, 2002). It is through this process that empathic concern is directed towards members of the outgroup (Thomas et al., 2009). Supporting the connection between empathic concern and bystander anti-racism, Pedersen and Thomas (2012) found that when asked about the emotions they would feel when witnessing racial discrimination, empathy for the target was the second most common emotion reported by participants.

Given that in reality, Indigenous Australians are indeed disadvantaged relative to non-Indigenous Australians (e.g. ABS, 2006a, 2006b; 2008), the possibility arises that nonIndigenous Australians may also come to experience empathic concern through recognition of this 'state' of disadvantage. As such, empathic concern might be experienced in response to situational factors that make outgroup (relative to ingroup) disadvantage salient, or in response to a general awareness that in comparison to the ingroup, the outgroup is indeed disadvantaged. Whatever the case, although Pedersen and Thomas (2012) noted the frequent report of empathic concern for the target of discrimination, due to their qualitative focus they did not assess its ability to predict bystander anti-racism. Thus, there are currently no quantitative studies that examine this possible relationship.

\section{Prejudice}

Prejudice can be conceptualised as negative opinions, feelings, and attitudes towards the outgroup and its members (Crandall et al., 2002). As mentioned earlier, research suggests that people generally behave in ways that are in line with the attitudes they hold (Ajzen \& Fishbein, 2005; Glasman \& Albarracin, 2006), suggesting that individuals with higher levels of prejudice towards an outgroup might be less inclined to speak up against that group's discrimination. Indeed, prejudice towards an outgroup has been associated with negative attitudes towards outgroup 
affirmative action programs (Awad, Cokley, \& Ravitch, 2005; Ellis, Kitzinger, \& Wilkinson, 2002) and a reduced likelihood of providing help to that group (Kluegel \& Smith, 1983).

\section{Socio-Demographics}

Also of interest are the relationships that have been found between prejudice and certain socio-demographic variables. For example, higher levels of prejudice have been significantly correlated with lower levels of formal education (Pedersen \& Hartley, 2012), being older (Pedersen, Beven, Walker, \& Griffiths, 2004), and right-wing political preference (Hodson \& Busseri, 2012; Whitley, 1999). Being male has also been linked to greater prejudice levels (Pedersen \& Walker, 1997), and is related to poorer attitudes toward affirmative action on behalf of minority groups (Kravitz \& Plantania, 1993). In contrast, however, other research has failed to find a correlation between gender and affirmative action attitudes (Awad et al., 2005). Also relevant to the present study is the notion that social norms, which prescribe the protection of women (Felson, 2000), may allow them to feel more at ease to engage in bystander anti-racism than their male counterparts because they may feel protected from the consequences of doing so.

In addition to the relationship found between age and prejudice, some research has found correlations between age and helping behaviour. Amato (1985) found that older participants were more likely to engage in planned formal helping, defined as providing help in ways that were planned in advance, and given within an organised context (non-profit organisations or community groups, rather than to friends, family or individual strangers). Amato argued that the relationship between age and formal helping was indicative of there being a stage within one's life cycle at which individuals are better equipped to engage in formal helping.

Amato did not, however, elaborate on why a given stage of one's life would have this effect. Based on Amato's definition of planned helping, it is clear that bystander antiracism would best be described as unplanned or spontaneous helping, as one can never know in advance when racial discrimination will be encountered. There is little research that has investigated the predictors of this form of helping; thus, it is unknown whether this relationship exists with respect to unplanned helping. For this reason, whether a relationship exists between age and bystander anti-racism will be further explored in the present study.

With respect to the socio-demographic variables outlined here, as they have been linked to prejudice, and prejudice has been linked to reduced levels of outgroup helping, it is worth considering whether they might also link directly with bystander anti-racism.

\section{Fear and Anger (Response Emotions)}

It has been suggested that contextual factors of discriminatory situations may have a bearing on the likelihood of bystander anti-racism (Nelson et al., 2011). Supporting this notion, fear of the perpetrator, or more specifically, of retaliation by the perpetrator, has been linked to the reduced likelihood of confronting name-callers in schools (Aboud \& Miller, 2007) and those who express sexism (Swim \& Hyers, 1999). Thus, fear may render action unlikely because the benefits of intervention are outweighed by the costs (Good et al., 2012; Kowalski, 1996). Additionally, some authors (e.g., Nelson et al., 2011) have also suggested that anger as a response to racial discrimination may motivate engagement in bystander action.

Anger focused research suggests that this emotion is experienced when a situation is deemed unfair (e.g., Batson et al., 2007; Mikula, Scherer, \& Athenstaedt, 1998). In addition, as anger results in high levels of arousal, it is an action-oriented emotion, motivating a direct and in the moment' challenge to the agents responsible for the perceived unfairness (Averill, 1983; Thomas et al., 2009). As racial discrimination is likely to be appraised as unfair, and bystander anti-racism requires that bystanders act immediately in response to instances of racial discrimination, it seems possible that anger may play a very specific role in motivating bystander anti-racism. Supporting this, Pedersen and Thomas (2012) found that anger towards the perpetrator was one of the most commonly reported emotions with respect to instances of racial discrimination. Whether fear and anger are specifically able to predict bystander anti-racism, however, remains yet to be examined.

\section{Overview of the Present Study}

Although there is a large body of literature available with respect to various pro-social behaviours, the specific act of bystander anti-racism remains relatively unexplored (Nelson et al., 2011). As such there is a lack of direct evidence as to what factors may predict bystander antiracism. The present study aimed to address this need using an exploratory approach. Specifically, the first aim was to explore whether variables shown to be associated with various pro-social behaviours and attitudes would also be associated with the intention to engage in bystander antiracism on behalf of Indigenous Australians. Due to the data collection constraints of the present study, bystander anti-racism intentions were measured rather than the behaviours themselves. Although it would be ideal to measure actions rather than intentions, Ajzen's (1991) theory of planned behaviour suggests that behavioural intentions do often lead to actual behaviour.

Supporting this position, in a meta-analysis exploring the efficacy of the theory of planned behaviour, Armitage and Conner (2001) found that self-reported behavioural intentions were indeed significantly correlated with actual behaviours $(r=.47)$. Similar results have also been found by other authors (e.g., Randall \& Wolff, 1994; Sheeran \& Orbell, 1998). Taken together, these studies support the measurement of action intentions where the measurement of actual behaviour is not possible. 
The variables included in the present study were national identity, collective guilt, empathic concern, prejudice, socio-demographic variables such as age, gender, political preference, level of education, and the response emotions fear and anger. As briefly touched on above, everyday racism is especially insidious and has to date been difficult to address. Yet, due to the 'average person' level at which bystander anti-racism occurs, it is well positioned to target this form of racism. In light of this, an everyday racism type scenario was used in the present study.

The second aim was to ascertain which related variables might predict the intention to engage in bystander antiracism. Using the independent variables which showed significant initial bivariate correlations with action intentions, a hierarchical multiple regression was used to build equations to predict bystander anti-racism intentions.

\section{Method}

\section{Social and Community Online Research Database (SCORED)}

The sample was recruited from Murdoch University's SCORED. Individuals must live in Australia and be over 18 years of age to register with SCORED. Only nonIndigenous Australians were eligible to participate in our survey. Individuals who are registered with SCORED receive points for every survey they complete. When they have accumulated a given number of points they are able to redeem their points for a prize, such as a store voucher. Individuals were contacted via an email that informed them that the online survey was open for participation. Participants provided implicit consent by completing and submitting the survey.

\section{Participants and Procedure}

One hundred and fifty participants were recruited from the database throughout July and August 2012; however, one participant's data was removed from analysis as they indicated an Indigenous Australian origin, leaving 149 participants. The mean age of the sample was 44 years $(S D=14.37$, range $=19-73$ years $)$ and there were slightly more female (54.9\%) than male participants (45.1\%). The majority of participants reported Anglo-Saxon ancestry (75.9\%), followed by other European (12.8\%) and Asian (6.4\%) ancestry, while the remaining five percent indicated they were 'mixed'. The sample lived predominantly in Western Australia (71.2\%), New South Wales (9.4\%) and Victoria $(7.9 \%)$, with the remainder $(11.5 \%)$ of participants being distributed throughout the Australian Capital Territory, Queensland, South Australia, and Tasmania. $60.4 \%$ of those in Western Australia lived in the Perth metropolitan area.

The sample leaned largely towards left-wing (51.1\%) as opposed to right-wing politics $(24.4 \%)$, while $24.5 \%$ of participants reported being 'neither'. The sample was well educated, with $77.8 \%$ having completed or at least commenced some form of post-school education. Data collected by the Australian Bureau of Statistics (ABS, 2010;
2011) show that in 2009, of the Western Australian population aged between $25-64$ years, $62 \%$ had obtained a non-school qualification, while the 2011 census reported a larger population of males (50.3\%) than females (49.7\%) in Western Australia. In comparison, the present study's sample contained more females and was more educated than the general population.

\section{Measures}

The survey ${ }^{1}$ consisted of four primary sections that included socio-demographic, social-psychological, bystander anti-racism intentions, and emotion measures. All of the following scales were presented as an online survey via the database website, and in the order in which they are described below. A 7-point scale that ranged from strongly disagree (1) to strongly agree (7) was used for the items in each scale, such that higher scores reflect higher levels of each construct. Where such a scoring system was not used, it will be described below.

Socio-demographics. Participants were asked to indicate their age, gender $(1=$ male, $2=$ female $)$, political preference $(1=$ left, $7=$ right $)$, education level $(1=$ pre-school, $11=$ higher degree such as $\mathrm{PhD}$ or Masters, part or complete), ancestry/cultural background, and state and city of residence.

National identity. The ingroup identification scale constructed by Leach et al. (2008) was used to measure participants' level of national identification. The scale has been shown to be reliable (see Leach et al., 2008, p. 150). Participants indicated the extent to which they agreed or disagreed with various items in the scale. Examples of items used include 'I feel a bond with Australians' and 'I think that Australians have a lot to be proud of.

Collective guilt. A five-item collective guilt scale was constructed based on that of Doosje and colleagues (1998). The items were rewritten to reflect the Indigenous Australian/Australian context. Doosje and colleagues found this scale to be reliable $(\alpha=.84)$. Examples of the items used include 'I feel regret for the harmful past actions of Australians toward Indigenous Australians' and 'I don't think that Australians today should feel guilty about the negative things done to Indigenous Australians'.

Empathic concern. The five-item empathic concern scale used by Pedersen et al. (2004) was used to measure the degree to which participants empathised with and were concerned about Indigenous Australians. Some items were slightly reworded for clarity. Pedersen and colleagues found this scale to be satisfactory $(\alpha=.69)$. Examples of the items used include 'I often empathise with Indigenous Australians' and 'I don't have much sympathy for Indigenous Australians'. The empathic concern scale was placed prior to the scenario and the bystander anti-racism intention measure so that it would measure empathic concern with respect to Indigenous Australians specifically, rather than as a response emotion to witnessing discrimination. 
Attitudes Towards Indigenous Australians (ATIA). This scale was also taken from Pedersen et al. (2004), and was used to measure participants' racism levels towards Indigenous Australians. The ATIA is comprised of 18 items that are a mix of 'old fashioned' and 'modern' statements, and was found to be very reliable $(\alpha=.93)$. Examples of the items used in the ATIA include 'Indigenous Australians would be lost without white Australians in today's society', and 'Indigenous people work as hard as anyone else'.

Bystander anti-racism intentions. A bystander scenario was adapted from Pedersen et al. (2011a), and was used to gauge how likely participants were to intervene when witnessing an instance of racial discrimination against Indigenous Australians. The scenario involved a low risk interpersonal context, and aimed to represent a form of racism that one might encounter on a day to day basis (everyday racism). Participants were asked to imagine that they were sitting with colleagues when their discussion turns to Indigenous Australian issues. One colleague states: 'They mostly are a bunch of lazy bastards', while the others agree and continue the discussion in a very negative way. Using a 7-point scale that ranged from extremely unlikely (1) to extremely likely (7), participants were then asked to indicate how likely it was that they would speak up or intervene in the scenario.

Fear and anger. To measure level of fear in response to the scenario, participants indicated the extent to which they agreed or disagreed with four statements such as 'This situation makes me feel afraid'. The level of anger in response to the scenario was measured in the same way, with statements such as 'This situation makes me feel furious'. Both the fear and anger scales were adapted from those used by Mackie, Devos, and Smith (2000), who found them to be reliable $(\alpha=.89$ and $\alpha=.87$, respectively). Van Zomeren, Spears, Fischer, and Leach (2004) also used a variant of the Mackie et al. (2000) anger scale in their three studies, finding it to be reliable in each ( $\alpha=$.86-.91). Furthermore, Van Zomeren et al. found that anger as measured by this scale was predictive of collective action tendencies, suggesting that it may useful in assessing the relationship between anger and the intention to engage in bystander anti-racism in the present study.

\section{Results}

\section{Descriptives}

Composite scores ranged from 1-7 and were calculated by averaging item scores for each scale. Higher scores reflect higher levels of the construct. The descriptive statistics for each scale are displayed in Table 1 and include the reliability coefficients, the scale means and standard deviations, and the number of items in each scale (k). Alpha coefficients were very good for all scales.

\section{Table 1}

Descriptives For All Scales $N=149$

\begin{tabular}{lllrl}
\hline Scale & Mean & \multicolumn{1}{l}{$S D$} & \multicolumn{1}{c}{$\kappa$} & $\alpha$ \\
\hline National identity & 5.32 & 1.02 & 14 & .94 \\
Collective guilt & 4.43 & 1.51 & 5 & .81 \\
Empathic concern & 4.64 & 1.42 & 5 & .85 \\
Prejudice & 3.04 & 1.31 & 18 & .95 \\
Anger & 4.97 & 1.63 & 4 & .93 \\
Fear & 3.31 & 1.40 & 4 & .84 \\
Bystander anti-racism intentions & 5.15 & 1.71 & 1 &
\end{tabular}

Note. Range for each scale $=1-7, \kappa=$ No. of items.

\section{Correlations}

Table 2 presents the bivariate correlations among the predictor variables. Most important are the correlations between the predictor variables and the criterion variable (bystander anti-racism intentions).

Every variable except level of education was significantly correlated with bystander anti-racism intentions. Female participants indicated a greater intention to engage in bystander anti-racism than did males, as did participants who reported lower levels of national identification. Being older, politically left inclined, feeling a greater level of collective guilt about historical wrongdoings, and a greater level of empathic concern toward Indigenous Australians were all associated with a greater likelihood of intervening on behalf of Indigenous Australians. Additionally, and perhaps not surprisingly, participants who reported less prejudice toward Indigenous Australians also indicated a greater likelihood of intervening. Relative to the scenario itself, those who felt greater levels of anger reported a greater intention to intervene. Unexpectedly, however, participants who felt greater fear indicated a greater likelihood of intervening than participants who reported lower levels of fear.

\section{Predictors of Bystander Anti-Racism Intentions}

A hierarchical multiple regression equation was employed to explore what proportion of variance in bystander antiracism intentions could be both uniquely and collectively accounted for by the predictor variables. Only the predictor variables that showed significant correlations with bystander anti-racism intentions were included in the regression equation; thus, education was not used in the equation. As previous research indicates that sociodemographic variables are less predictive of prejudice than social-psychological variables (e.g., Pedersen et al., 2004), socio-demographic variables were entered into step one. Social-psychological variables were entered into step two, and the response emotion variables were entered into step three. The emotion variables were entered last in an effort to identify whether anger and/or fear in response to the scenario predicted bystander anti-racism intentions once all other predictor variables were accounted for. Table 3 presents the bystander anti-racism intention equation.

The socio-demographic variables entered on step 1 collectively accounted for a significant 14\%, $F(3,110)=$ 
Table 2

Intercorrelations Among Variables $(N=149)$

\begin{tabular}{|c|c|c|c|c|c|c|c|c|c|c|c|}
\hline & 1 & 2 & 3 & 4 & 5 & 6 & 7 & 8 & 9 & 10 & 11 \\
\hline 1. Bystander anti-racism intentions & - & & & & & & & & & & \\
\hline 2. Age & $.21^{*}$ & - & & & & & & & & & \\
\hline 3. Education & -.08 & $-.22^{* *}$ & - & & & & & & & & \\
\hline 4. Political preference & $-.30 * * *$ & .002 & -.05 & - & & & & & & & \\
\hline 5. Gender & $.23 * *$ & -.005 & -.03 & $-.24^{* *}$ & - & & & & & & \\
\hline 6. National identity & $-.21 *$ & .06 & -.15 & $.28^{* *}$ & -.08 & - & & & & & \\
\hline 7.Collective guilt & $.41 * * *$ & .09 & -.02 & $-.42 * * *$ & $.23^{* *}$ & -.08 & - & & & & \\
\hline 8. Empathic concern & $.56^{\star * *}$ & $.17^{*}$ & -.01 & $-.41 * * *$ & $.18^{*}$ & -.13 & $.64^{* * *}$ & - & & & \\
\hline 9. Prejudice & $-.61 * * *$ & -.04 & -.10 & $.57^{\star * *}$ & $-.24^{* *}$ & $.26 * *$ & $-.64^{* * *}$ & $-.76^{* * *}$ & - & & \\
\hline 10. Anger & $.53^{* * *}$ & .04 & .03 & $-.36 * * *$ & $.18^{*}$ & -.10 & $.58^{* * *}$ & $.62^{* * *}$ & $-.75^{* * *}$ & - & \\
\hline 11. Fear & $.26^{* *}$ & .13 & -.04 & $-.24^{* *}$ & $.17^{*}$ & -.16 & $.54^{* * *}$ & $.47^{* * *}$ & $-.43^{* * *}$ & $.56^{* * *}$ & - \\
\hline
\end{tabular}

Note: Pearson product-moment correlation was used; higher scores reflect higher levels (or likelihood) of each variable; Re: gender, $1=$ male, $2=$ female; Re: political preference, $1=$ left, $2=$ right; $^{*}=p \leq .05 ;{ }^{* *}=p \leq .01 ;{ }^{* * *}=p \leq .001$, all 2-tailed.

$6.02, p=.001$, of the variance in bystander anti-racism intentions, while age and political preference (i.e., left vs. right) each uniquely accounted for a significant proportion of the variance, $5 \%, t(110)=2.49, p=.01$, and $6 \%, t(110)=-2.77, p=.007$, respectively. On step 2 , the inclusion of the five psychological variables accounted for an additional and significant $24 \%$ of the variance, bringing the shared variance to a significant $38 \%, F(7$, 106) $=9.17, p<.001$. Of all the variables included at step 2, only empathic concern and prejudice uniquely accounted for a significant proportion of variance, $4 \%$, $t(106)=2.51, p=.01$, and $4 \%, t(106)=-2.57, p=.01$, respectively.

On step 3, the increase in shared variance accounted for by fear and anger was non-significant, but the total shared variance was $40 \%, F(9,104)=7.60, p<.001$. Cohen (1988) suggests that a combined effect of this magnitude can be considered large $\left(f^{2}=.66\right)$. In the final equation only age and empathic concern had significant beta weights, uniquely explaining $2.6 \%, t(104)=2.11, p=$ .04 , and $4 \%, t(104)=2.64, p=.01$, of the variance in bystander anti-racism intentions, respectively. In summary, being older and having a greater level of empathic concern for Indigenous Australians uniquely predicted intentions to engage in bystander anti-racism.

\section{Discussion}

The present study had two main aims. The first was to explore whether variables that have previously been associated with pro-social behaviours and attitudes might also be associated with bystander anti-racism on behalf of Indigenous Australians. The second was to ascertain whether the associated variables that were revealed during the exploration of Aim 1 might predict the intention to engage in bystander anti-racism; in other words, what were the strongest predictors. The findings relevant to these aims will now be discussed.

\section{Correlates of Bystander Anti-Racism Intentions (Aim 1)}

Social-psychological variables. The finding that participants with a stronger Australian identity reported a lesser likelihood to intervene on behalf of Indigenous Australians supports previous research (Cuddy et al., 2007; Levine et al., 2005; Tarrant et al., 2009) and an assumption of SIT whereby individuals are less likely to help those who do not belong to their ingroup than those who do (Tajfel \& Turner, 1986). On the other hand, why lower levels of national identity were related to greater intention to intervene is not exactly clear. SIT (Tajfel \& Turner, 1986) states that because the groups we belong to are perceived

\begin{tabular}{|c|c|c|c|c|c|c|c|}
\hline Variables & $s r^{2}$ & $\beta(a)$ & $\beta(b)$ & $\beta(c)$ & $R^{2}$ change & $R^{2}$ & Adj. $R^{2}$ \\
\hline Step 1 & & & & & $.14^{* * *}$ & $.14^{* * *}$ & $.12^{* * *}$ \\
\hline Age & $.05^{* *}$ & $.22^{* *}$ & .15 & $.17^{*}$ & & & \\
\hline Political preference (left vs. right) & $.06 * *$ & $-.25 * *$ & .02 & .02 & & & \\
\hline Gender & .01 & .13 & .08 & .09 & & & \\
\hline Step 2 & & & & & $.24^{* * *}$ & $.38^{* * *}$ & $.34^{* * *}$ \\
\hline National identity & .003 & & -.06 & -.10 & & & \\
\hline Collective guilt & .008 & & -.12 & -.11 & & & \\
\hline Empathic concern & $.04^{* *}$ & & $.31^{* *}$ & $.33^{* *}$ & & & \\
\hline Prejudice & $.04^{* *}$ & & $-.35^{* *}$ & -.23 & & & \\
\hline Step 3 & & & & & .02 & $.40 * * *\left(\right.$ Total $\mathrm{R}^{2)}$ & $.34^{* * *}$ \\
\hline Anger & .02 & & & .21 & & & \\
\hline Fear & .01 & & & -.13 & & & \\
\hline
\end{tabular}

Note: ${ }^{*} p \leq .05,{ }^{* *} p \leq .01,{ }^{* * *} p \leq .001$ (all two tailed). $\beta$ (a) denotes beta weight for variables after step $1 ; \beta(\mathrm{b})$ denotes beta weights for variables after step $2 ; \beta($ c) denotes beta weights for variables after step 3 . 
as extensions of ourselves, we are motivated to help those who are similar to us and who belong to our groups in order to derive positive affect about the self.

However, just because one identifies to a lesser extent with being Australian, does not mean that they identified strongly with Indigenous Australians. It is equally feasible that those who identified to a lesser extent with being Australian may have identified to a greater extent with another group (not measured) which was either inclusive of Indigenous Australians, or whose values prescribe prosocial behaviour such as bystander anti-racism. A similar suggestion was made by McGarty and colleagues (2005), where the authors argued that at least in Australia, where the national identity construct is complex and even ambiguous, an opinion-based group identity may be more relevant. It is important to note is that although significant, the correlation between national identity and bystander anti-racism intentions was weak, and it is therefore possible that a more relevant group identity would result in a stronger correlation.

In line with previous research, greater levels of collective guilt were associated with a greater likelihood to engage in bystander anti-racism (e.g., Doosje et al., 1998; Halloran, 2007; Pedersen \& Thomas, 2012), as was greater empathic concern (e.g., Eisenberg \& Miller, 1987; Karancanta \& Fitness, 2006; Pedersen \& Thomas, 2012; Oswald, 1996). In other words, participants who experienced higher levels of guilt on behalf of their ingroup with respect to the past and present mistreatment of Indigenous Australians, and who reported greater levels of concern for the welfare of Indigenous Australians, were more likely to speak up against their discrimination.

Some authors have expressed concern that collective guilt leads to pro-social action that allows for the resolution of feelings of guilt, but not more long-term, possibly more arduous, or even costly forms of pro-social action that is aimed at restoring the balance between those who are advantaged and those who are not (e.g., Iyer et al., 2004; Thomas et al., 2009). Yet, the positive association between collective guilt and bystander anti-racism intentions in the present study suggests there are distinct societal advantages of collective guilt. As bystander anti-racism involves voicing one's disapproval with racism, it is well positioned to help establish anti-racism norms (Nelson et al., 2011) that would in the long term help diminish the occurrence of racism, and may also lead to the evolution of more positive attitudes and feelings toward the target group, who in this case are Indigenous Australians.

Relative to this finding, it is interesting to note that, as shown in Table 2, national identity and collective guilt were not correlated. Although there was no prediction made in relation to these two variables, it might be expected that if low levels of Australian national identity were associated with higher levels of bystander anti-racism intentions, these variables might have been related, given that the collective guilt scale involved an Australian verses Indigenous Australian dichotomy. Yet, the lack of such a finding again raises the question of how functional an 'Australian' identity is when discussing Indigenous Australian relations, adding weight to the above argument that another group identity is possibly more relevant to the issue of bystander anti-racism at least in regards to Indigenous Australians.

Finally, in support of the attitude-behaviour hypothesis (Ajzen \& Fishbein, 2005; Glasman \& Albarracin, 2006), as well as the findings of previous research (e.g., Awad et al., 2005; Ellis et al., 2002; Kluegel \& Smith, 1983), prejudice towards Indigenous Australians was negatively correlated with bystander anti-racism intentions. Those who reported more negative attitudes toward Indigenous Australians indicated that they were less likely to intervene on their behalf when witnessing an instance of discrimination against them.

Response emotion variables. In contrast to the assertions of previous research (Aboud \& Miller, 2007; Swim \& Hyers, 1999), a positive correlation between fear and bystander anti-racism intentions emerged in our sample. That is, greater fear was significantly associated with greater intent to engage in bystander anti-racism. This finding is very much contrary to arguments regarding the effect of cost-benefit appraisals on action which suggest that when the cost of action outweighs the possible benefits, the likelihood of such action is reduced (Good et al., 2012; Kowalski, 1996). Attempting to apply this argument would mean that, as participants felt more fearful, the perceived benefits to intervene also increased; yet on the surface this seems unlikely.

Although it is unclear why this relationship emerged, there is a possibility to be considered. Because the scenario was of low risk, it is unlikely that participants felt fear out of concern for their physical safety, yet it is plausible that fear of being judged by one's colleagues may have been what was experienced by participants. We can only speculate that if participants agreed with, or were indifferent about the statements being made, that it would be unlikely that they would feel fear of being judged. However, if one was to disagree with the statements being made, and possibly feel that one ought to speak up, then it is possible that thoughts surrounding how one's colleagues might react to a rebuttal would enter one's mind.

So why might the fear of being judged not only be ineffective at stopping people from speaking up against discrimination, but in fact relate to a greater likelihood of speaking up? If we look at Table 2, the correlation between anger and fear indicates that participants who reported greater levels of anger towards the scenario also indicated greater levels of fear. With caution, we suggest that for fear to work as an obstacle it may perhaps have to be fear of a specific consequence. For example, fear of being physically hurt or of being incarcerated for engaging in illegal behaviour may well deter people from engaging in certain pro-social behaviours, but fear or anxiety about how your colleagues might view you if you challenge their 
prejudiced views might not. Additionally, higher levels of anger were associated with higher levels of fear. It is possible that fear of judgement in this case was not enough to override the effect of being angered by racism, and as such those people were still more willing to speak up.

Finally, in support of past research (e.g., Pedersen \& Thomas, 2012) the correlations between anger and bystander anti-racism intentions were significant. Participants who indicated greater anger in response to the discrimination scenario also reported a greater likelihood of engaging in bystander anti-racism. It has been argued that when individuals evaluate a situation as being unfair, they are likely to experience anger (e.g., Batson, 2007; Mikula et al., 1998) which can motivate them to take action against the unfairness (Averill, 1983; Thomas et al., 2009). Although our findings cannot with certainty indicate how participants viewed the scenario with respect to fairness, they do lend strength to the argument that anger could be considered an action-oriented emotion.

Socio-demographic variables. Participants who were older and female reported a greater likelihood of engaging in bystander anti-racism. These findings support previous findings which have found correlations between age and helping behaviour (e.g., Amato, 1985), and between gender and attitudes towards affirmative action programs for minority groups (e.g., Kravitz \& Plantania, 1993). Furthermore, our findings on the relationship between political preference and action build on previous findings regarding the relationship between political preference and prejudice (e.g., Hodson \& Busseri, 2012; Whitley, 1999).

With respect to the relationship between age and bystander anti-racism intentions, it is also worth noting that our findings expand those of Amato (1985), as he only investigated and found a correlation between age and planned helping behaviour, whereas our results indicate that a correlation also exists between age and unplanned helping behaviour. It is possible that Amato's argument for his finding might also explain the relationship found in the present study; that certain later stages in life better position individuals to help others. However, we would add that rather than being specifically relative to a stage in one's life, an increased likelihood of engaging in bystander antiracism might instead reflect the fact that older individuals have had a greater range of life experiences and therefore a greater range of life and other skills. These skills may then render them more self-confident than their younger counterparts with respect to their ability to help others and to confront or challenge those with whom they disagree.

Regarding the findings on gender, it may be that our results reflect the concept of cooperative self-interest (Kravitz \& Plantania, 1993), which stipulates that women are more willing than men to support other marginalised and discriminated against groups due to their belief that establishing equality for others will ultimately make their own battle for gender-based equality easier. We also suggest that women might better understand the experience of being marginalised, such that they experience more empathy for others who are also marginalised. On the other hand, it may be that women reported a greater likelihood to intervene because, unlike men, they felt safeguarded by social norms that frown upon violence and aggression towards women (Felson, 2000). With respect to political preference, participants who preference the right are generally more socially conservative, resistant to change, and tend to align with policies which maintain intergroup inequity (Hodson \& Busseri, 2012; Whitley, 1999). It is thus understandable that a left political preference was associated with a greater intent to engage in bystander anti-racism, while a preference to the right was associated with a lower level of bystander anti-racism intentions.

As level of formal education has often been associated with prejudice (e.g., Pedersen \& Hartley, 2012; Pedersen et al., 2008), and prejudice has both in the present study and in past studies been associated with pro-social behaviour, it seemed reasonable that level of education might also independently relate to bystander anti-racism intentions. This, however, was not the case, as our findings showed no evidence of a correlation between level of education and bystander anti-racism intentions.

In summary, intention to engage in bystander antiracism was significantly associated with age, political preference, gender, national identity, collective guilt, empathic concern, prejudice, anger and fear.

\section{Predicting Bystander Anti-Racism Intentions (Aim 2)}

On step 1 of the hierarchical multiple regression, only age and political preference emerged as unique predictors; however, when the social-psychological variables were entered on step 2, age and political preference were no longer unique predictors. Of the social-psychological variables included, only empathic concern and prejudice significantly accounted for a unique proportion of variance in bystander anti-racism intentions. When anger and fear were added to the equation on step 3, however, the only significant predictors were age and empathy. In other words, being older predicted a greater likelihood of engaging in bystander anti-racism, as did greater empathic concern for Indigenous Australians.

Although some of the included variables did not on any step account for a unique proportion of variance in bystander anti-racism intentions, it is important to note that at every step in the regression, the proportion of variance accounted for by the combination of variables was significant. This indicates that although only age and empathic concern uniquely predict the intention to engage in bystander anti-racism, the remainder of the included variables (political preference, gender, national identity, collective guilt, prejudice, anger, and fear) are nevertheless important. This is further supported by the aforementioned significant correlations. Moreover, the significant beta weights of political preference on step 1, and of prejudice on step 2, indicate that these variables are perhaps 
more relevant than the non-significant variables, but less so than age and empathic concern.

That age was found to be predictive of bystander antiracism intentions builds on previous research (Amato, 1985) and our earlier findings by demonstrating that age is not only associated with but also predictive of unplanned/spontaneous helping behaviour. As a detailed discussion on age has already taken place above, for reasons of parsimony, we will simply reiterate that as a result of having greater 'life' experience, older individuals may be better prepared and therefore more confident in their ability to effectively speak up in everyday racial discriminatory situations. Furthermore, while younger individuals might refrain from speaking up out of concern for how they might be perceived by others (work colleagues in this case), older individuals may be less concerned with the perceptions of others and, therefore, such a concern is unlikely to inhibit them from speaking up. The collection of qualitative data in future research may serve to clarify this finding and either confirm or disconfirm our interpretation.

The finding that one's level of empathic concern can predict one's likelihood of engaging in bystander antiracism is in line with the findings of previous authors who have explored empathic concern for the homosexual community (Karacanta \& Fitness, 2006), for fellow students (Oswald, 1996), and for African Americans (Iyer et al., 2003, Study 2). It appears that concern for the welfare of another serves as motivation to act in a way that may benefit that person or the group to which they belong. Yet could it be that we measured trait empathic concern rather than empathic concern specifically for Indigenous Australians? Admittedly, this possibility cannot be conclusively ruled out; however, while Pedersen and colleagues (2004) found that trait empathic concern and prejudice towards Indigenous Australians were weakly correlated $(r=-.28)$, they found that empathic concern specifically for Indigenous Australians, and prejudice toward them was more strongly correlated $(r=-.63)$. As the correlation between empathic concern and prejudice in the present study mirrors that found by Pedersen and colleagues some support is offered to the notion that it was indeed empathic concern for Indigenous Australians specifically, that was measured in the present study.

\section{Strengths, Limitations, and Future Research}

There are some limitations to the present study that should be considered. First, although action intentions have been shown to significantly relate to actual behaviour (e.g., Armitage \& Conner, 2001; Randall \& Wolff, 1994; Sheeran \& Orbell, 1998), there is nevertheless a possibility that social desirability bias may influence self-reported intentions. In this instance, our ability to measure actual bystander behaviour was limited by the online nature of the present study and therefore, action intentions were the next closest measurable construct as indicated by the literature.

Second, as the present sample was a good deal more educated than the general Western Australian commu- nity (ABS, 2010), the sample may not adequately reflect the sentiment held with respect to Indigenous Australians in the general population. Unfortunately, this may be a problem that is inherent to using participant databases where sign-up is voluntary, yet because community response rates continue to decline (Pedersen \& Hartley, 2012), participant databases often provide the best access to relatively large samples. On the other hand, the fact that the present sample was well educated does not exclude them from being important. Furthermore, it may be of that individuals with a greater level education are best positioned to engage in bystander anti-racism.

Strengths of the present study include that the present paper responds to the need for more research to be carried out within the specific field of bystander anti-racism. In fact, this study is one of the first to examine the correlates and predictors of bystander anti-racism specifically. This is especially important given that everyday racisms are the forms most often encountered on a daily basis by minority groups (Beagan, 2003; Swim et al., 2003), and it is these everyday racisms which bystanders are best positioned to combat as they often occur at an interpersonal or social level (Nelson et al., 2011).

Future research could explore why age, a sociodemographic variable, emerged as pertinent over and above most of the social-psychological variables; a finding that is in contrast to past research with regard to prejudice (e.g. Pedersen et al., 2004). A focus on qualitative data may help to clarify this. It was suggested that older individuals may be more likely to engage in bystander anti-racism because they are less concerned with how they are perceived by others and because through greater life experience, they may better possess the skills required to successfully intervene. Future research could look to ascertain whether this is in fact the case. As mentioned earlier, it may be that opinion-based identities, such as an activist identity for example, may better relate to bystander anti-racism than did national identity. This possibility could also be explored in the future. Finally, researchers should also aim to replicate the present study with different target groups.

\section{Practical Implications}

Understanding the predictors of bystander anti-racism relates to the possibility of increasing its occurrence through targeted intervention. A possible reverse interpretation for our findings regarding age is that younger individuals may not perceive themselves as well equipped enough to intervene in instances of racial discrimination, or to challenge those who they have certain types of relationships with. As such, it is viable that younger individuals could be taught through educational interventions how to effectively communicate with others about issues surrounding racism and other cultures more generally, such that they might feel more confident about engaging in bystander anti-racism (Nelson et al., 2011). In fact, a few studies have already begun evaluating such programs (Pedersen 
\& Thomas, 2012; Pedersen et al., 2011a) and they appear to be successful.

These educational programs may also address the other predictor that emerged. Reporting greater empathic concern for Indigenous Australians was also predictive of intentions to engage in bystander anti-racism. Educational interventions which involve learning about the cultures and histories of minority groups are likely to improve one's ability to focus on the 'other' and as such, increase the experience of empathic concern for the relative group (Pedersen et al., 2011b).

\section{Concluding Statements}

In conclusion, the present study demonstrated that many of the variables associated with pro-social attitudes and behaviours are also associated with the intention to engage in bystander anti-racism specifically. Furthermore, it was revealed that age and empathic concern uniquely predicted the intention to engage in bystander anti-racism on behalf of Indigenous Australians. As racial discrimination has the capacity to cause significant harm to a target (Larson et al., 2007; Paradies et al., 2008), their group, and to a community as a whole, it is pertinent that ways of effectively reducing racial discrimination are investigated. Bystander anti-racism has the immediate effect of stopping racial discrimination, while possibly also resulting in longer term benefits such as the establishment of antiracism norms and the reduction of future discriminatory behaviour (Blanchard et al., 1991; Czopp \& Monteith, 2003; Czopp et al., 2006; Nelson et al., 2011).

The findings from this research may be used to inform the design of educational intervention programs aimed at providing the necessary skills for individuals to feel confident in speaking up against racial discrimination. By increasing the likelihood of bystander anti-racism, closing the gap between the advantaged and disadvantaged may be just that one step closer.

\section{Endnote}

1 Initially, a comparison of the variables within the present study was planned according to whether or not participants read an empathy inducing narrative. As there were no effects, this aspect has not been included in the main study. It is noted, however, in an attempt to minimise the 'file drawer' problem.

\section{References}

Aboud, F.E., \& Miller, L. (2007). Promoting peer intervention in name-calling. South African Journal of Psychology, 37(4), 803-819.

Ajzen, I. (1991). The theory of planned behavior. Organizational Behavior and Human Decision Processes, 50, 179-211.

Ajzen, I., \& Fishbein, M. (2005). The influence of attitudes on behavior. In D. Albarracín, B.T. Johnson, \& M.P. Zanna (Eds.), The handbook of attitudes (pp. 173-221). Mahwah, NJ: Erlbaum.
Amato, P.R. (1985). An investigation of planned helping behavior. Journal of Research in Personality, 19(2), 232-252. doi:10.1016/0092-6566(85)90031-5

Armitage, C.J., \& Conner, M. (2001). Efficacy of the theory of planned behaviour: A meta-analytic review. British Journal of Social Psychology, 40(4), 471-499.

Asch, S.E. (1956). Studies of independence and conformity: A minority of one against a unanimous majority. Psychological Monographs, 70, 1-70

Asch, S.E. (1955). Opinions and social pressure. Scientific American, 193(5), 31-35. doi:10.1038/scientificamerican1155-31

Australian Bureau of Statistics (ABS). (2011). 2011 Census quickstats (Western Australia). Canberra, Australia: Author. http://www.censusdata.abs.gov.au/census_services/get product/census/2011/quickstat/5

Australian Bureau of Statistics (ABS). (2010). Western Australian statistical indicators (Cat. No. \#1367.5). Canberra, Australia: Author. http://www.abs.gov.au/ausstats/abs@.nsf/Products/ C14BFFF4F481ABDDCA25781D000D6963?opendocument

Australian Bureau of Statistics (ABS). (2009). Prisoners in Australia (Cat. No. 4517.0). Canberra, Australia: Author.

Australian Bureau of Statistics (ABS). (2008). The health and welfare of Australia's Aboriginal and Torres Strait islander peoples (Cat. No. 4704.0). Canberra, Australia: Author. Retrieved from Ausstats: www.abs.gov.au/ausstats

Australian Bureau of Statistics (ABS). (2006a). Population characteristics, Aboriginal and Torres Strait islander peoples (Cat. No. 4731.0). Canberra, Australia: Author. Retrieved from www.abs.gov.au/ausstats

Australian Bureau of Statistics (ABS). (2006b). Deaths, Australia (Cat. No. 3302.0). Canberra, Australia: Author. Retrieved from www.abs.gov.au/ausstats

Averill, J.R. (1983). Studies on anger and aggression: implications for theories of emotion. The American Psychologist, 38(11), 1145-1160. doi: 10.1037/0003-066X.38.11.1145

Awad, G.H., Cokley, K., \& Ravitch, J. (2005). Attitudes toward affirmative action: A comparison of color-blind versus modern racist attitudes. Journal of Applied Social Psychology, 35(7), 1384-1399. doi: 10.1111/j.1559-1816.2005.tb02175.x

Batson, C.D., Zerger, T., Kennedy, C.L., Nord, L., Stocks, E.L., Fleming, D.A., ... Zerger, T. (2007). Anger at unfairness: Is it moral outrage? European Journal of Social Psychology, 37(6), 1272-1285. doi:10.1002/ejsp.434

Batson, C.D., Chang, J., Orr, R., \& Rowland, J. (2002). Empathy, attitudes, and action: Can feeling for a member of a stigmatized group motivate one to help the group? Personality and Social Psychology Bulletin, 28(12), 1656-1666.

Batson, C.D., Polycarpou, M.P., Harmon-Jones, E., Imhoff, H.J., Mitchener, E.C., Bednar, L.L., ... Highberger, L. (1997). Empathy and attitudes: Can feeling for a member of a stigmatized group improve feelings toward the group? Journal of Personality and Social Psychology, 72(1), 105-118. doi:10.1037/0022-3514.72.1.105

Beagan, B.L. (2003). 'Is this worth getting into a big fuss over?' Everyday racism in medical school. Medical Education, 37(10), 852-860. doi:10.1046/j.1365-2923.2003.01622.x 
Beresford, Q. (2001). Homeswest versus Aborigines: Housing discrimination in Western Australia. Australian Aboriginal Studies, 2, 40-46.

Berman, G., \& Paradies, Y. (2010). Racism, disadvantage and multiculturalism: Towards effective anti-racist praxis. Ethnic and Racial Studies, 33(2), 214-232. doi:10.1080/ 01419870802302272

Blanchard, F.A., Lilly, T., \& Vaughn, L.A. (1991). Reducing the expression of racial prejudice. Psychological Science, 2(2), 101-105. doi:10.1111/j.1467-9280.1991.tb00108.x

Bloch, B., \& Dreher, T. (2009). Resentment and reluctance: Working with everyday diversity and everyday racism in southern Sydney. Journal of Intercultural Studies, 30(2), 193209. doi:10.1080/07256860902766982

Bourke, C., \& Cox, H. (1994). Two lands: One land. In C. Bourke, E. Bourke, \& B. Edwards (Eds.), Aboriginal Australia (second edition, pp. 56-76). Brisbane, Australia: University of Queensland Press.

Brown, R., Gonzalez, R., Zagefka, H., Manzi, J., \& Cehajic, S. (2008). Nuestra culpa: Collective guilt and shame as predictors of reparation for historical wrongdoings. Journal of Personality and Social Psychology, 1, 75-90. doi:10.1037/00223514.94.1.75

Cialdini, R.B., \& Trost, M.R. (1998). Social influence: Social norms, conformity, and compliance. In D.T. Gilbert, S.T. Fiske, \& G. Lindzey (Eds.), The handbook of social psychology (Vol. 2, pp. 151-192). New York: McGraw-Hill.

Cohen, J. (1998). Statistical power analysis for the behavioural sciences (2nd ed.). Hillsdale, NJ: Erlbaum.

Crandall, C.S., Eshleman, A., \& O’Brien, L. (2002). Social norms and the expression and suppression of prejudice: The struggle for internalization. Journal of Personality and Social Psychology, 82(3), 359-378. doi:10.1037/0022-3514.82.3.359

Cuddy, A.J.C., Rock, M.S., \& Norton, M.I. (2007). Aid in the aftermath of hurricane Katrina: Inferences of secondary emotions and intergroup helping. Group Processes \& Intergroup Relations, 10(1), 107-118. doi:10.1177/1368430207071344

Czopp, A.M., Monteith, M.J., \& Mark, A.Y. (2006). Standing up for a change: Reducing bias through interpersonal confrontation. Journal of Personality and Social Psychology, 90(5), 784-803. doi:10.1037/0022-3514.90.5.784

Czopp, A.M., \& Monteith, M.J. (2003). Confronting prejudice (literally): Reactions to confrontations of racial and gender bias. Personality \& Social Psychology Bulletin, 29(4), 532-544. doi:10.1177/0146167202250923

Doosje, B.E.J., Branscombe, N., Spears, R., \& Manstead, A. (1998). Guilty by association: When one's group has a negative history. Journal of Personality and Social Psychology, 75(4), 872-886.

Dunn, K., \& Nelson, J.K. (2011). Challenging the public denial of racism for a deeper multiculturalism. Journal of Intercultural Studies, 32(6), 587.

Eisenberg, N., \& Miller, P.A. (1987). The relation of empathy to prosocial and related behaviors. Psychological Bulletin, 101(1), 91-119. doi:10.1037/0033-2909.101.1.9

Ellis, S.J., Kitzinger, C., \& Wilkinson, S. (2002). Attitudes towards lesbians and gay men and support for lesbian and gay human rights among psychology students. Journal of Homosexuality, 44(1), 121-138.

Felson, R.B. (2000, March). The normative protection of women from violence. Sociological Forum, 1 (15), 91-116.

Fraser, C.O., \& Islam, M.R. (2000). Social identification and political preferences for one nation: The role of symbolic racism. Australian Journal of Psychology, 52(3), 131-137. doi:10.1080/00049530008255380

Good, J.J., Moss-Racusin, C.A., \& Sanchez, D.T. (2012). When do we confront? Perceptions of costs and benefits predict confronting discrimination on behalf of the self and others. Psychology of Women Quarterly, 36(2), 210-226. doi:10.1177/0361684312440958

Glasman, L.R., \& Albarracín, D. (2006). Forming attitudes that predict future behavior: A meta-analysis of the attitudebehavior relation. Psychological Bulletin, 132(5), 778-822. doi:10.1037/0033-2909.132.5.778

Halloran, M.J. (2007). Indigenous reconciliation in Australia: Do values, identity and collective guilt matter? Journal of Community \& Applied Social Psychology, 17, 1-18. doi:10.1002/casp.876

Harth, N.S., Kessler, T., \& Leach, C.W. (2008). Advantaged group's emotional reactions to intergroup inequality: The dynamics of pride, guilt, and sympathy. Personality \& Social Psychology Bulletin, 34(1), 115-129. doi:10.1177/ 0146167207309193

Henry, B.R., Houston, S., \& Mooney, G. (2004). Institutional racism in Australian healthcare: A plea for decency. Medical Journal of Australia, 180, 517-519.

Hodson, G., \& Busseri, M.A. (2012). Bright minds and dark attitudes: Lower cognitive ability predicts greater prejudice through right-wing ideology and low intergroup contact. Psychological Science, 23(2), 187-195. doi:10.1177/ 0956797611421206

Iyer, A., Leach, C.W., \& Crosby, F.J. (2003). White guilt and racial compensation: The benefits and limits of self-focus. Personality and Social Psychology Bulletin, 29(1), 117-129. doi:10.1177/0146167202238377

Iyer, A., Leach, C.W., \& Pedersen, A. (2004). Racial wrongs and restitutions: The role of guilt and other group-based emotions. In N.R. Branscombe \& B. Doosje (Eds.), Collective guilt: international perspectives (pp. 262-283). Cambridge, UK: Cambridge University Press.

Karacanta, A., \& Fitness, J. (2006). Majority support for minority outgroups: The roles of compassion and guilt. Journal of Applied Social Psychology, 36(11), 2730-2749.

Klandermans, B. (2002). How group identification helps to overcome the dilemma of collective action. American Behavioral Scientist, 45(5), 887-900. doi:10.1177/000276420204500500

Kluegel, J.R., \& Smith, E.R. (1983). Affirmative action attitudes: Effects of self-interest, racial affect, and stratification beliefs on whites' views. Social Forces, 61(3), 797-824.

Kowalski, R.M. (1996). Complaints and complaining: Functions, antecedents, and consequences. Psychological Bulletin, 119(2), 179-196.

Kravitz, D.A., \& Platania, J. (1993). Attitudes and beliefs about affirmative action: Effects of target and of respondent sex 
and ethnicity. Journal of Applied Psychology, 78(6), 928-938. doi:10.1037/0021-9010.78.6.928

Larson, A., Gillies, M., Howard, P., \& Coffin, J. (2007). It's enough to make you sick: The impact of racism on the health of Aboriginal Australians. Australian and New Zealand Journal of Public Health, 31(4), 332-339. doi:10.1111/j.17536405.2007.00079.x

Leach, C.W., Snider, N., \& Iyer, A. (2002). 'Poisoning the consciences of the fortunate': The experience of relative advantage and support for social equality. In I. Walker \& H.J. Smith (Eds.), Relative deprivation: Specification, development, and integration (pp. 136-163). Cambridge, UK: Cambridge University Press.

Leach, C.W., Van Zomeren, M., Zebel, S., Vliek, M.L.W., Pennekamp, S.F., Doosje, B., Ouwerkerk, J.P., \& Spears, R. (2008). Group-level self-definition and self-investment: A hierarchical (multicomponent) model of in-group identification. Journal of Personality and Social Psychology, 95(1), 144-165. doi:10.1037/0022-3514.95.1.144

Levine, M., Prosser, A., Evans, D., \& Reicher, S. (2005). Identity and emergency intervention: How social group membership and inclusiveness of group boundaries shape helping behavior. Personality \& Social Psychology Bulletin, 31(4), 443-453. doi:10.1177/0146167204271651

Levine, M., \& Thompson, K. (2004). Identity, place, and bystander intervention: Social categories and helping after natural disasters. The Journal of Social Psychology, 144(3), 229245. doi:10.3200/SOCP.144.3.229-245

Nelson, J.K., Dunn, K.M., \& Paradies, Y. (2011). Bystander antiracism: A review of the literature. Analyses of Social Issues and Public Policy, 11(1), 263-284.

Mackie, D.M., Devos, T., \& Smith, E.R. (2000). Intergroup emotions: Explaining offensive action tendencies in an intergroup context. Journal of Personality and Social Psychology, 79(4), 602-616.

Masser, B., \& Phillips, L. (2003). 'What do other people think?' The role of prejudice and social norms in the expression of opinions against gay men. Australian Journal of Psychology, 55(3), 184-190. doi:10.1080/0004953042000298652

McGarty, C., Pedersen, A., Leach, C.W., Mansell, T., Waller, J., \& Bliuc, A. (2005). Group-based guilt as a predictor of commitment to apology. The British Journal of Social Psychology, 44, 659-680. doi:10.1348/014466604X18974

Mellor, D. (2004). Responses to racism: A taxonomy of coping styles used by Aboriginal Australians. American Journal of Orthopsychiatry, 74(1), 56-71. doi:10.1037/0002-9432.74. 1.56

Mikula, G., Scherer, K.R., \& Athenstaedt, U. (1998). The role of injustice in the elicitation of differential emotional reactions. Personality and Social Psychology Bulletin, 24(7), 769-783. doi:10.1177/0146167298247009

Miller, C.T. (1993). Majority and minority perceptions of consensus and recommendations for resolving conflicts about land use reform. Personality \& Social Psychology Bulletin, 19, 389-398.

Mooney, G. (2003). Institutionalised racism in Australian public services. Indigenous Law Bulletin, 5(26), 10-12.
Oswald, P.A. (1996). The effects of cognitive and affective perspective taking on empathic concern and altruistic helping. The Journal of Social Psychology, 136(5), 613-23. doi:10.1080/00224545.1996.9714045

Paradies, Y., Harris, R., \& Anderson, I. (2008). The impact of racism on Indigenous health in Australia and Aotearoa: Towards a research agenda. Darwin, Australia: Cooperative Research Centre for Aboriginal Health. Retrieved from http://www.crcah.org.au/publications/downloads/RacismReport.pdf

Pedersen, A., Beven, J., Walker, I., \& Griffiths, B. (2004). Attitudes toward Indigenous Australians: The role of empathy and guilt. Journal of Community and Applied Social Psychology, 14, 233-249. doi:10.1002/casp.771

Pedersen, A., Griffiths, B., \& Watt, S.E. (2008). Attitudes toward outgroups and the perception of consensus: All feet do not wear one shoe. Journal of Community \& Applied Social Psychology, 18(6), 543-557. doi:10.1002/casp.964

Pedersen, A., \& Hartley, L.K. (2012). Prejudice against Muslim Australians: The role of values, gender and consensus. Journal of Community and Applied Social Psychology, 22, 239-255. doi:10.1002/casp.1110.

Pedersen, A., Paradies, Y., Hartley, L.K., \& Dunn, K. (2011a). Bystander antiprejudice: Cross-cultural education, links with positivity towards cultural 'outgroups' and preparedness to speak out. Journal of Pacific Rim Psychology, (1), 19-30.

Pedersen, A., \& Thomas, E.F. (2012). Taking action against the prejudice and discrimination of Muslim people: The role of collective identity and emotion. Unpublished manuscript.

Pedersen, A., \& Walker, I. (1997). Prejudice against Australian Aborigines: Old fashioned and modern forms. European Journal of Social Psychology, 27, 561-587.

Pedersen, A., Walker, I., Paradies, Y., \& Guerin, B. (2011b). How to cook rice: Ingredients for teaching anti-prejudice. The Australian Psychologist, 46, 55-63.

Randall, D.M., \& Wolff, J.A. (1994). The time interval in the intention-behaviour relationship: Meta-analysis. British Journal of Social Psychology, 33, 405-418.

Sheeran, P., \& Orbell, S. (1998). Do intentions predict condom use? Meta-analysis and examination of six moderator variables. British Journal of Social Psychology, 37, 231-250.

Sibley, C.G., \& Barlow, F.K. (2009). Ubiquity of whiteness in majority group national imagination: Australian = white, but New Zealander does not. Australian Journal of Psychology, 61(3), 119-127. doi:10.1080/00049530802239300

Stephan, W.G., \& Finlay, K. (1999). The role of empathy in improving intergroup relations. Journal of Social Issues, 55(4), 729-743. doi:10.1111/0022-4537.00144

Swim, J.K., \& Hyers, L.L. (1999). Excuse me - What did you just say?!: Women's public and private responses to sexist remarks. Journal of Experimental Social Psychology, 35(1), 68-88. doi:10.1006/jesp.1998.1370

Swim, J.K., Hyers, L.L., Cohen, L.L., Fitzgerald, D.C., \& Bylsma, W.H. (2003). African American college students' experiences with everyday racism: Characteristics of and responses to these incidents. Journal of Black Psychology, 29(1), 38-67. doi:10.1177/0095798402239228 
Tajfel, H. (1974). Social identity and intergroup behaviour. Social Science Information, 13(2), 65-93. doi:10.1177/ 053901847401300204

Tajfel, H., \& Turner, J.C. (1986). The social identity theory of intergroup behavior. In S. Worchel \& W.G. Austin (Eds.), Psychology of intergroup relations (pp. 7-24). Chicago: Nelson-Hall.

Tarrant, M., Dazeley, S., \& Cottom, T. (2009). Social categorization and empathy for outgroup members. The British Journal of Social Psychology, 48(3), 427-446. doi:10.1348/ 014466608X373589

Terry, D.J., \& Hogg, M.A. (1996). Group norms and the attitudebehavior relationship: A role for group identification. Personality and Social Psychology Bulletin, 22(8), 776-793. doi:10.1177/0146167296228002

Thomas, E.F., McGarty, C., \& Mavor, K.I. (2009). Transforming 'apathy into movement': The role of prosocial emotions in motivating action for social change. Personality and Social Psychology Review, 13(4), 310-333.
Van Zomeren, M., Spears, R., Fischer, A.H., \& Leach, C.W. (2004). Put your money where your mouth is! Explaining collective action tendencies through group-based anger and group efficacy. Journal of Personality and Social Psychology, 87, 649-664.

Vescio, T.K., Sechrist, G.B., \& Paolucci, M.P. (2003). Perspective taking and prejudice reduction: The meditational role of empathy arousal and situational attributions. European Journal of Social Psychology, 33, 455472.

Watt, S.E., \& Larkin, C. (2010). Prejudiced people perceive more community support for their views: The role of own, media, and peer attitudes in perceived consensus. Journal of Applied Social Psychology, 40(3), 710-731. doi:10.1111/j.15591816.2010.00594.x

Whitley, B.E. (1999). Right-wing authoritarianism, social dominance orientation, and prejudice. Journal of Personality and Social Psychology, 77(1), 126-134. doi:10.1037/00223514.77.1.126 